\title{
Udder measurements and milk production in two Awassi sheep genotypes and their crosses
}

\author{
L. Iñiguez, ${ }^{* 1}$ M. Hilali, ${ }^{*} D$. L. Thomas, $†$ and G. Jesry* \\ *International Center for Agricultural Research in the Dry Areas (ICARDA), PO Box 5466, Aleppo, Syria \\ †Department of Animal Sciences, University of Wisconsin-Madison, 1675 Observatory Drive, Madison 53706
}

\begin{abstract}
To improve the effectiveness of community-based breeding programs for increased milk production, the values of different udder measurements for predicting milk production traits during the milking period were assessed over 3 yr on 273 Awassi ewes. Machine milking of ewes began after weaning, $56 \mathrm{~d}$ after parturition, and continued until the milk yield of the ewes was $<200$ $\mathrm{mL} / \mathrm{d}$. Milk yield obtained by hand milking and milk composition were measured weekly, and days in milk, total milk yield, and total yields of protein, fat, and nonfat solids in milk were calculated for each ewe. On d 70 of milking, morphological traits of the whole udder (circumference, width, height, and length), udder cistern (height), and teats (length, width, and position score) were measured. On the same day, the milk yield of ewes was recorded by hand milking. Positive and moderate to strong correlations $(\mathrm{r}=0.36$ to 0.76$)$ between udder circumference and width, teat width, and milk production traits of total milk yield, and total yields of protein, fat, and nonfat solids were found. However, a more accurate predictor of milk production traits was milk yield on d 70, as higher positive correlations between this variable and the milk production traits were found ( $\mathrm{r}=0.63$ to 0.89 ). Nine farmers were invited to independently estimate the hand-milked milk yield performance of a sample of 169 ewes (d 15 to 45 of milking) by visually observing each ewe and making a subjective linear score (1 to 5 ). Their assessments were significantly correlated with milk yield on the day of the observation $(\mathrm{r}=0.52)$, total milk yield $(\mathrm{r}=0.50)$, and days in milk $(\mathrm{r}=0.45)$. Considering the perception details provided by farmers concerning each of the subjective linear scores, it was found that most predictive linear udder measurements of udder circumference and width and teat width identified in this study were implicit in these scores. The predictive ability of the measurements studied have practical implications for
\end{abstract}

Received December 5, 2008.

Accepted May 20, 2009.

${ }^{1}$ Corresponding author: Luisiniguez8@gmail.com community-based breeding programs involving improvement of milk production-not just in Syria, but in other countries in dry areas as well-because it is possible for experienced farmers to visually assess milk production of dairy ewes or take simple udder measurements with predictive value.

Key words: Awassi sheep, udder linear measurement, milk production trait

\section{INTRODUCTION}

Awassi sheep are indigenous sheep that are adapted to the dry areas of western Asia (Kassem, 2005). Although improved Awassi sheep is a high-yielding dairy breed exploited under intensive conditions (Epstein, 1985), the production of Awassi sheep also contributes to the livelihoods of a large number of small-scale and resource-poor producers in developing Middle Eastern countries, particularly Turkey, Syria, Jordan, and Lebanon. Awassi sheep are utilized for both meat and milk production, with a population estimated at 21 million in Syria in 2007 (FAOSTAT, 2008). In areas of these countries that are more suitable for fodder production, the breed is used in semi-intensive dairy production systems that focus on satisfying an increasing demand for dairy products (Kassem, 2005).

Although some sheep breeding programs are available in these countries, they are mostly centralized and limited to breeding centers without major effect on the large Awassi base population, and farmers claim they lack access to improved genotypes (Iñiguez, 2006). Without sources for improved animals, most farmers use rams produced in their own flocks and a few rams exchanged with other farmers. In all cases, farmers follow their own selection criteria when deciding the types of animals to be used for breeding purposes.

In response to the demand for improved breeding stock, the International Center for Agricultural Research in Dry Areas (ICARDA) concluded that communitybased breeding plans are needed that rely on simple and sustainable recording schemes that farmers agree to follow (Iñiguez, 2006). It is expected that, within this context, local knowledge concerning selection criteria 
will be combined with the use of measurable variables for assessing animals for milk production potential. The direct measurement of milk production is usually cumbersome and may not be possible in the majority of production systems. Some easy-to-obtain measurements that farmers are familiar with, which could predict important milk production traits, would be useful. Udder morphology measurements, their relationships with milk production traits and aptitude for mechanical milking, and their usefulness for genetic improvement have been studied in other sheep breeds such as Chios (Mavrogenis et al., 1988), Churra (Fernández et al., 1995), East Friesian (McKusick et al., 1999); Manchega and Lacaune (Rovai et al., 1999; Caja et al., 2000), and Sardinian (Casu et al., 2006).

Correlations between udder and direct milk production measures were estimated to assess the potential value of udder and simple milk measurements in onfarm evaluations and community-based breeding plans. The study also involved a visual assessment of the ewes by northern Syrian farmers to determine if this local knowledge could effectively predict ewe milk production and integrate practical and sustainable recording procedures to be followed by dairy sheep smallholders.

\section{MATERIALS AND METHODS}

\section{Udder Measurements}

During 3 consecutive years, from 2003 to 2006, a total of 273 milk-producing Awassi ewes of second and greater parity and not involved in other experimental work were selected for the study from ICARDA's sheep flock at Tel Hadya in northern Syria. This flock included 3 Awassi genotypes: the Syrian Awassi (S), the Turkish Awassi (T), and crossbred ewes between the 2 genotypes (TS). Ewes were weaned from their lambs
$56 \mathrm{~d}$ after parturition and then machine-milked twice daily, at 0630 and $1630 \mathrm{~h}$, respectively, during the milking period using a double-12 milking machine (Bonsaglia and C. srl, Brescia, Italy) but hand milked during the milk recording test-days following the same routine. Hand milking on the recording test-days was adopted because the milking machine was not equipped with milk meters. Milk yield of ewes was recorded weekly by hand milking at both the morning and evening milking on the recording day. The milking period ended for each ewe when her milk yield was $<200 \mathrm{~mL}$ on a recording day. At each recording day, morning milk samples were obtained from each ewe to determine immediately, with no preservative addition or storage under refrigeration, the percentage of protein, fat, and nonfat solids in the milk by using a MilkoScan 133B device (Foss Electric, Hillerød, Denmark). The DIM from weaning onward was recorded, and yields during the milking period (total milk yield and total fat, protein, and nonfat solids yields) were estimated from information gathered on recording days following the method of Thomas (2003). There were 379 lactations produced by the 273 ewes under observation.

On d 70 of lactation (14 d after the start of the milking period), individual milk yields by hand milking and morphological traits of the whole udder (circumference, width, height, and length), udder cistern (height), and teats (length, width, and position score) were measured by following the protocol proposed by Labussière et al. (1981) and McKusick et al. (1999). The udder measurements and teat position scores were taken at about 0700 to $0800 \mathrm{~h}$, immediately after the morning milking. A ribbon tape was used for measuring udder circumference and teat length, and a caliper was used for measuring udder length, width, and height, cistern height, and teat width.

Table 1. Udder morphology in Awassi dairy sheep $(\mathrm{n}=379$ lactations produced by 273 ewes)

\begin{tabular}{|c|c|c|c|c|c|}
\hline Measurements and scores & Mean & $\mathrm{SE}$ & Minimum & Maximum & $\mathrm{CV}$ \\
\hline \multicolumn{6}{|l|}{ Udder measurements } \\
\hline Udder circumference, cm & 40.1 & 0.3 & 20.5 & 52.5 & 12.1 \\
\hline Udder width, cm & 13.5 & 0.1 & 9.2 & 19.1 & 12.2 \\
\hline Udder length, cm & 10.7 & 0.1 & 5.9 & 15.0 & 14.5 \\
\hline Udder height, cm & 20.4 & 0.1 & 13.9 & 27.9 & 12.4 \\
\hline Cistern height, m & 3.4 & 0.1 & 0.5 & 7.8 & 36.2 \\
\hline Teat length, cm & 3.4 & 0.04 & 1.9 & 6.4 & 22.2 \\
\hline Teat width, cm & 2.2 & 0.02 & 1.2 & 4.3 & 19.4 \\
\hline Teat position, score & 2.5 & 0.03 & 2.0 & 5.0 & 22.8 \\
\hline \multicolumn{6}{|l|}{ Milk production measurements } \\
\hline Milk yield on d 70 of lactation, ${ }^{1} \mathrm{~mL}$ & 972 & 19 & 250 & 2,650 & 38.9 \\
\hline Total milk yield, kg & 79.4 & 2.4 & 2.4 & 296.4 & 59.9 \\
\hline DIM & 96.2 & 2.1 & 11.0 & 221.0 & 43.1 \\
\hline Total fat yield, $\mathrm{kg}$ & 4.7 & 0.2 & 0.1 & 20.7 & 62.0 \\
\hline Total protein yield, kg & 4.2 & 0.1 & 0.2 & 17.4 & 64.0 \\
\hline Total nonfat solids yield, kg & 9.0 & 0.3 & 0.3 & 33.1 & 60.1 \\
\hline
\end{tabular}

${ }^{1}$ After 14 DIM after parturition. 
A total of 86 ewes $(32 \%)$ had repeated milk production and udder measurement records in the $3 \mathrm{yr}$ of the study.

\section{Local Knowledge}

The International Center for Agricultural Research in Dry Areas had worked previously with farmers in the El Bab area of northern Syria to develop a participatory adaptive research plan to improve dairy sheep productivity. Nine farmers from El Bab were invited to ICARDA's research station in 2008 to give their assessment of the potential milk yield of milking ewes. Farmers were asked about their criteria for evaluating animals and whether these involved the udder measurements considered in this study. Farmers were then asked to individually rank a set of 169 ewes from ICARDA's research flock that had been milking for 15 to $45 \mathrm{~d}$ after weaning ( $56 \mathrm{~d}$ after lambing), using their own criteria, on a 1 to 5 scale $(1=$ a very poor milkproducing ewe, $5=$ an outstanding milk-producing ewe). Most of the ewes in this set were different from the 273 ewes involved in the main udder measurement study and included only S and TS ewes, a small proportion of twinning ewes, and a relatively balanced number of animals per age group (45, 47, 45, and 32 ewes for the groups including 2-, 3-, 4- and 5-yr-old ewes, respectively). Ewes were evaluated by the farmers in the milking parlor before the morning milking, which was conducted by hand. Milk production of each ewe was recorded at each milking (a.m. and p.m.) both on the day of scoring to determine daily milk yield and weekly over the whole milking period to calculate total milk yield and DIM.

\section{Statistical Analysis}

Statistical analyses were conducted using SAS software v. 9.1 (SAS Institute Inc., Cary, NC). Quantitative values were analyzed by GLM with year, age, and litter size of the ewe and genotype of the ewe as fixed effects. With similar fixed effects, the teat position scores were analyzed using a cumulative Logit link function in the GENMOD procedure of SAS. Correlations between all different variables measured were estimated by the CORR procedure of SAS, after adjusting data according to the effects implicit in the linear models. Spearman rank correlations between scores by different farmers were estimated along with correlations between these scores, milk yield on the scoring day, total milk production, and DIM. As no statistical differences for these traits were found concerning breed and litter size effects, simple correlations by individual farmers were calculated within age groups and then combined according to the procedure described by Snedecor and Cochran (1967). Repeatabilities for the udder measurements with higher correlations with milk production traits were calculated using REML in the VARCOMP procedure of SAS, from a mixed model with genotype, year, litter size, and ewe age as fixed effects and the repeated effect of the ewe over years as a random effect. The teat position repeatability was also calculated with the same procedure assuming that this trait was linear. Considering the most suitable measurements for predicting total milk yield, equations were built with year, genotype, age, and litter size as fixed effects, along with covariates including udder circumference, milk yield at d 70 of lactation, and DIM.

\section{RESULTS AND DISCUSSION}

\section{Udder Morphology Measurements}

Udder measurements have been studied previously in Awassi sheep (Gootwine et al., 1980) and other dairy sheep breeds such as Lacaune (Labussière et al., 1981), Chios (Mavrogenis et al., 1988), Churra (Fernández et al., 1995), East Friesian (McKusick et al., 1999), and Manchega and Lacaune (Caja et al., 2000; Rovai et al., 2008). Udder measurements between studies and flocks can vary considerably, partly depending on when the measurements were taken relative to the milking period and the time of milking. In our case, udder measurements were performed immediately after the morning milking. Timing and method of measurements in this study (70 d after lambing) were comparable to those of McKusick et al. (1999) who assessed a US population of high percentage East Friesian dairy sheep. Udder circumference of Awassi ewes (Table 1) was 6.1 and $6.6 \mathrm{~cm}$ smaller than in East Friesian (McKusick et al., 1999) and Churra sheep (Fernández et al., 1995), respectively, and, although the average of the East Friesian and Churra fell within the Awassi range of values, only $13 \%$ of the Awassi ewes have udder circumferences equal to or larger than the averages of East Friesian and Churra. A more elongated udder seems to be typical of the Awassi as this breed displayed a higher mean udder height compared with the $14.6 \mathrm{~cm}$ in East Friesian ewes (McKusick et al., 1999). The height of Awassi udders also exceeded that of Manchega and Lacaune sheep measured in Spain (Rovai et al., 1999; Such et al., 1999) and Lacaune measured in Slovakia (Milerski et al., 2006) and was similar to Sarda (Labussière, 1988) and Chios ewes (Mavrogenis et al., 1988).

Udder width and udder length averages of Awassi (Table 1) were similar to those of East Friesian ewes (McKusick et al., 1999). The Awassi udders were also 
similar in width to Lacaune (Such et al., 1999; Milerski et al., 2006; Rovai et al., 2008) and Churra udders (Fernández et al., 1995), and in length to Lacaune (Such et al., 1999; Rovai et al., 1999, 2008), Manchega (Rovai et al., 1999, 2008), and Sarda udders (Labussière, 1988).

Considering the reduced size of cistern height, this measurement had a larger coefficient of variation $(\mathbf{C V}$; $36 \%$ ) compared with other udder measurements (Table 1 ), which suggests difficulties in recording this trait with precision. This observation concurs with Milerski et al. (2006) and Fernández et al. (1995) who found large CV for this trait in Chios and Churra ewes, respectively. The average of cistern height in Awassi was greater than in Lacaune (Rovai et al., 1999, 2008; Such et al., 1999), Churra (Fernández et al., 1995), and Manchega (Rovai et al., 1999, 2008), and similar to that of Sarda (Labussière, 1988) and East Friesian (McKusick et al., 1999).

Apparently, teat length and width are not widely variable between dairy sheep breeds: teat lengths and widths of Awassi ewes (Table 1) were similar to those of Lacaune (Labussière, 1988; Such et al., 1999; Rovai et al., 2008), East Friesian (McKusick et al., 1999), Manchega (Rovai et al., 1999; Such et al., 1999), Churra (Fernández et al., 1995), Istrian crossbreds (Dzidic et al., 2004), Bergamasca (Emediato et al., 2008), and Tsigai and improved Valachian (Milerski et al., 2006), although slightly shorter than in Chios sheep (Mavrogenis et al., 1988). Consistent with Fernández et al. (1995) and McKusick et al. (1999), teat measurements displayed larger CV (ranging from 19.4 to $22.2 \%$; Table 1) than udder circumference, width, length, and height (CV ranging from 12.1 to $14.5 \%$; Table 1 ).

Teat position averaged a 2.5 score (Table 1); that is, vertical and slightly cranially oriented, somewhat similar to East Friesian sheep (McKusick et al., 1999) although with a large variability $(\mathrm{CV}=23.0 \%$; Table 1$)$ and less cranial than Churra (Fernández et al., 1995).

\section{Predictive Value of Udder and Simple Milk Measurements}

Considering that total milk yield was highly correlated with DIM, total fat yield, total protein yield, and total nonfat solids yield ( $\mathrm{r}=0.92$ to 0.99 ), focusing the analysis on total milk yield was justified.

Udder circumference and width and teat width and position had greater correlations with milk yield on $\mathrm{d}$ 70 and total milk yield ( $\mathrm{r}=0.49$ to 0.80$)$ than did other measurements (Table 2). Udder circumference and teat width have been shown to be significantly correlated with total milk yield and are considered good predictors of performance in other breeds such as Lacaune
(Labussière et al., 1981; Labussière, 1988), Chios (Mavrogenis et al., 1988), Zelazna (Charon, 1990), Churra (Fernández et al., 1995), East Friesian (McKusick et al., 1999), and Bergamasca (Emediato et al., 2008). Correlation was strong and significant between udder circumference and width $(\mathrm{r}=0.96)$, which was consistent with a similar association found in Churra ewes (Fernández et al., 1995); in addition, except with DIM, each of these traits had greater correlations with total fat, protein, and nonfat solids yields than did teat width (Table 2). Contrasting the low estimates of repeatability for udder circumference and width obtained by Fernández et al. (1995) in Churra ewes, our REML estimates of repeatability for these traits were higher: 0.50 and 0.38 , respectively; furthermore, the repeatability estimate for teat width was the highest (0.71), showing that udder circumference and teat width are relatively more consistent measurements from year to year. Thus, udder circumference and teat width appear to be the most useful of the udder measurements taken in this study for predicting total milk yield of Awassi sheep. The correlations between udder circumference and width with teat width were low to medium size and positive ( $\mathrm{r}=0.34$ and $\mathrm{r}=0.46$, respectively); however, they were higher than those obtained by Fernández et al. (1995) in Churra ewes and opposite to the negative correlations reported by Mavrogenis et al. (1988) in Chios ewes.

A medium to strong correlation was found between average teat position score with milk yield on d 70 of lactation and milk production traits of total milk yield, DIM, total fat yield, and total nonfat solids yield $(\mathrm{r}=$ 0.41 to 0.65 ), whereas the correlation with total protein yield was low $(r=0.25)$. The estimate of repeatability for teat position score was low (0.32), which is lower than in Churra ewes (Fernández et al., 1995); this and a large CV (Table 1) probably reflect inconsistent scoring over the years. The position of teats on the left and right sides of the udder displayed a high rank correlation $(\mathrm{r}=0.77, P<0.01)$, indicating some incidence of unbalanced udder halves within ewes. This trait is important in relation to machine milking in which a homogeneous type of udder in all animals is desirable.

Correlations of teat measurements, in particular concerning teat width with milk composition and quality traits, are not readily available in the literature. Our estimates differ from those of Mavrogenis et al. (1988) and McKusick et al. (1999) that reported no correlation between teat width and total milk yield and test-day milk yield.

An additional measurement with some ability for predicting production traits was cistern height although this negatively correlated with milk yield on d 70, total milk yield, total fat yield, total protein yield, and total 
Table 2. Correlations between udder linear measurements and milk production traits ${ }^{1}$

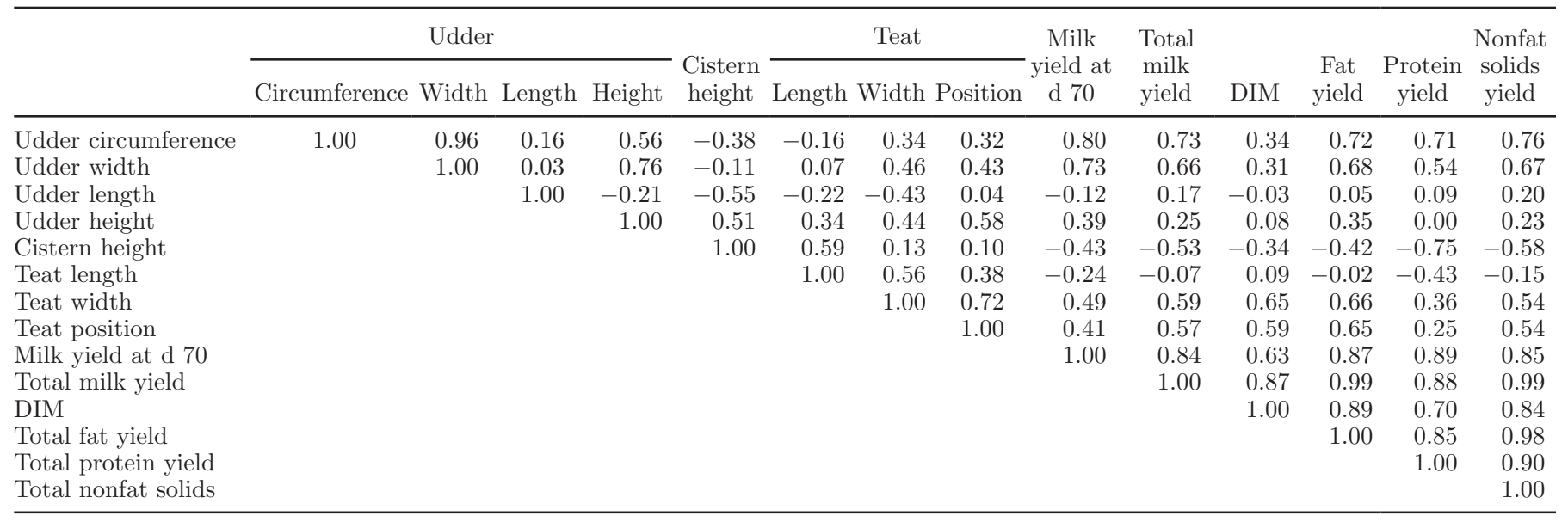

${ }^{1}$ All correlation values of $|\mathrm{r}| \leq 0.10$ are statistically nonsignificant.

nonfat solids yield ( $\mathrm{r}=-0.34$ to -0.75$)$; however, its measurement is more cumbersome and subject to more variation under field conditions than those involving udder circumference or teat width. This information contrasts with that of McKusick et al. (1999) who found positive relationships between cistern height and production traits in East Friesian ewes. Cistern height is apparently independent from udder circumference and width and teat width, as reflected in the low correlations with these variables (Table 2), a trend also observed in Churra sheep by Fernández et al. (1995).

Measurements that displayed low correlations with milk yield and other production traits included udder height, udder length, and teat length, making them unsuitable for predicting milk production performance. Udder height was previously shown to be significantly correlated with milk yield (Labussière et al., 1981; Mavrogenis et al., 1988; McKusick et al., 1999). Lack of relationships between milk yield traits and udder length was also shown by McKusick et al. (1999). The lowest correlations were found between teat length and the milk production traits of total milk yield, total fat yield, total protein yield, and total nonfat solids yield (Table 2). These results were similar to the findings of Mavrogenis et al. (1988) in Chios ewes and Emediato et al. (2008) in Bergamasca ewes. A medium correlation was found between teat length and teat width $(\mathrm{r}=$ 0.56), which is closer to the estimate found by Fernández et al. (1995) in Churra ewes.

Milk yield measured on d 70 of lactation had a higher and more significant correlation with the total yield traits of total milk yield, total fat yield, total protein yield, and total nonfat solids yield $(\mathrm{r}=0.84$ to 0.89$)$ than did any of the udder measurements, indicating the value of milk yield measurements, even if few are taken, in predicting total milk yields. This trait displayed a high CV (60\%) and a low repeatability (0.39).
Predictive udder measurements such as udder circumference, teat width, and milk yield on d 70 can be useful in screening procedures to establish a nucleus or group of high-producing animals at the start of a breeding cycle. During the implementation of a breeding program, other simple measurements such as DIM should not be overlooked as this trait has a strong correlation with the milk production traits considered in this study.

\section{Udder and Simple Milk Measurement Variability}

Differences between year of observation were marked $(P<0.01)$ for all udder measurements except teat width due mainly to lower values observed in 2004 compared with 2003 and 2005. In contrast, the least squares means of milk yield on d 70 showed a continuous and significant increase from 2003 to 2005. According to Iñiguez and Hilali (2009), these differences probably reflected both environmental changes during the period of study and the effect of culling in the flock.

There were no significant differences between genotypes for udder measurements except for teat width and teat position. For teat width and position the rank was $\mathrm{S}<\mathrm{TS}<\mathrm{T}$, with the teats of $\mathrm{T}$ being larger and in a more cranial position. The least squares means of teat width and position scores were, respectively, $2.2 \pm$ $0.03 \mathrm{~cm}$ and $2.4 \pm 0.04$ for $\mathrm{S} ; 2.3 \pm 0.04 \mathrm{~cm}$ and $2.5 \pm$ 0.06 for TS; and $2.4 \pm 0.08 \mathrm{~cm}$ and $3.0 \pm 0.11 \mathrm{~cm}$ for $\mathrm{T}$. The significant genotype differences for teat position contrasted with the lower repeatability found for this trait $(0.32)$. The repeatability of teat position in Churra (0.52; Fernández et al., 1995), as indicated earlier, was higher than our estimate, whereas Fernández et al. (1997) and Legarra and Ugarte (2005) reported a moderate heritability for teat placement, a trait that encompasses teat position, of 0.24 in Churra, and from 
0.38 to 0.42 in Latxa ewes, respectively. Considering that a structural trait may not vary over time, an improvement in the accuracy of assessing teat position, as suggested earlier, could make it possible to select within a population for the type of teat position for optimum machine milking.

The least squares means of milk yield on d 70 was greater $(P<0.05)$ for the T genotype $(1,189 \pm 73 \mathrm{~mL})$. Even though there was no significant difference between the least squares means of $\mathrm{S}(973 \pm 30 \mathrm{~mL})$ and TS $(1,018 \pm 42 \mathrm{~mL})$ genotypes, TS had an intermediate value between $\mathrm{T}$ and $\mathrm{S}$. Differences in milk production in these genotypes have been noted in the same flock by Iñiguez and Hilali (2009), showing the higher producing ability of $\mathrm{T}$ ewes and their crosses.

With the exception of udder length and teat length and width, age effects significantly changed all other udder measurements and milk yield on $\mathrm{d} 70$, with values that tended to peak at 4 to $5 \mathrm{yr}$ of age before declining thereafter. Similar effects and trends were found in earlier studies (Mavrogenis et al., 1988; Fernández et al., 1995) assessing lactation effects in Chios and Churra ewes, a condition that was confounded with age in this study.

Except for udder length, teat length, teat width, and teat position, ewes giving birth to twins and generally nursing twins before milking had significantly udder larger measurements. No significant effects due to litter size were found for milk yield on d 70 .

To synthesize the former information, linear equations were built incorporating the most suitable candidate measurements for predicting total milk yield while adjusting for ewe age and litter size (Table 3). The first equation was fitted with udder circumference alone as covariate for predicting total milk yield. The covariate estimate was positive and predicted about $5 \mathrm{~kg}$ of milk per additional centimeter in udder circumference. The $\mathrm{R}^{2}$ value of this equation almost doubled (from 0.36 to 0.65 ) with the addition of milk yield on $d 70$ as a second covariate, stressing the importance of including at least a simple milk yield evaluation while assessing the performance of ewes. The regression coefficients in this new equation were also positive and significant, with udder circumference having relatively more weight than milk yield on d 70 in influencing total milk yield. The best fit was obtained with the addition of DIM as covariate (Table 3). The inclusion of DIM removed the effects of age on total milk yield and increased the determination coefficient to $92 \%$; the corresponding regression coefficient had a relatively higher weight than udder circumference and milk yield on d70. The information provided by the first 2 equations could be suitable for strategies of screening for outstanding ewes, for elite or nucleus flocks, and for reducing time in evaluating candidate sires for selection, whereas the information of the third equation could suit regular recording schemes in a community-based breeding plan designed to ensure strategic and sustainable recording procedures for smallholders.

The inclusion of teat width along with udder circumference as covariates did not lead to a better fit $\left(\mathrm{R}^{2}=\right.$ 0.37) than that of the first equation with only udder circumference as covariate.

\section{Local Knowledge}

The scores of any one farmer were positively and significantly correlated to the scores of the other farmers $(r=0.64$ to 0.83$)$ indicating that farmers were using similar criteria to determine their scores. Farmers stated that udder width, hardiness, shape and position of teats, and the animal's temperament were important in their judgment of an animal's milk production potential. The 5 scores assessed by farmers had the following characteristics:

- Scores 4 and 5: Excellent to outstanding ewes with large, wide, and pliable udders that were symmetrical in shape. Teats were wide and greater than 9 to $10 \mathrm{~cm}$ in length (width of 4 fingers). Animals in this category were docile and manageable.

- Score 3: Good ewes with big udders but small teats, making milking difficult. Animals were docile.

- Score 2: Bad animals with hard, narrow, and small udders. Teats were thick and, in some cases, dripping some milk before the ewe was milked. Animals showed some degree of nervousness.

- Score 1: Undesirable ewes intended to be culled, with udders extremely hard, narrow, and long. Ewes showed a high degree of nervousness.

Note that the teat length targeted by farmers (scores 4 and 5) is today considered as a disqualifying defect for machine-milked sheep. Therefore, these scores should be considered exclusive for hand milking

The correlation coefficients between a farmer's scores and milk yield on the day of scoring $(\mathrm{r}=0.52)$, total milk yield $(\mathrm{r}=0.50)$, and DIM $(\mathrm{r}=0.45)$ revealed that the Awassi farmers of El Bab had skills and knowledge for assessing relatively accurately the production performance of a ewe. A subjective milk score, based on inspecting the udder size and fill, given to ewes within $24 \mathrm{~h}$ of parturition in US range sheep was estimated to be useful as a trait to improve sheep milk production (Snowder et al., 2001). It was not specifically inquired whether farmers also emphasize DIM during the productive life of a ewe; however, in other surveys conducted (M. Hilali; personal observation), farmers indicated 
Table 3. Least squares estimates for linear equations involving fixed effects due to year, genotype, ewe age, and ewe litter size, and covariates

\begin{tabular}{|c|c|c|c|}
\hline Fixed effects and covariates & \multicolumn{3}{|c|}{ Equation $^{1}$} \\
\hline \multicolumn{4}{|l|}{ Year } \\
\hline 2004 & $81.0 \pm 4.7$ & $73.4 \pm 3.5^{\mathrm{b}}$ & $72.2 \pm 1.7^{\mathrm{b}}$ \\
\hline 2005 & $90.0 \pm 4.4$ & $81.7 \pm 3.3^{\mathrm{a}}$ & $84.9 \pm 1.6^{\mathrm{a}}$ \\
\hline \multicolumn{4}{|l|}{ Genotype } \\
\hline \multicolumn{4}{|l|}{ Ewe age, yr } \\
\hline 2 & $85.5 \pm 5.4^{\mathrm{a}}$ & $84.6 \pm 4.0^{\mathrm{a}}$ & $79.9 \pm 1.9$ \\
\hline 3 & $93.0 \pm 5.4^{\mathrm{ab}}$ & $87.5 \pm 4.0^{\mathrm{ac}}$ & $80.1 \pm 1.9$ \\
\hline 4 & $88.1 \pm 5.9^{\text {abd }}$ & $79.4 \pm 4.4^{\text {ace }}$ & $80.6 \pm 2.1$ \\
\hline 5 & $84.4 \pm 5.5^{\mathrm{abdf}}$ & $78.7 \pm 4.1^{\text {acef }}$ & $80.0 \pm 1.9$ \\
\hline 6 & $72.1 \pm 5.5^{\text {acef }}$ & $70.4 \pm 4.1^{\text {bdef }}$ & $78.4 \pm 1.9$ \\
\hline Milk yield at $\mathrm{d} 70, \mathrm{~kg}$ of milk $/ \mathrm{mL}$ of change in milk yield at $\mathrm{d} 70$ & $\mathrm{NA}^{2}$ & $0.09 \pm 0.005^{* *}$ & $0.04 \pm 0.003^{* *}$ \\
\hline DIM, $\mathrm{kg}$ of milk/d of change in DIM & NA & NA & $0.78 \pm 0.02^{* *}$ \\
\hline Determination coefficient & 0.36 & 0.65 & 0.92 \\
\hline $\mathrm{CV}, \%$ & 49 & 36 & 17 \\
\hline
\end{tabular}

${ }^{\mathrm{a}-\mathrm{f}}$ Means within a column and fixed effect without a common superscript are statistically different.

${ }^{1}$ Equations include the following covariates: 1) udder circumference; 2) udder circumference and milk yield at d 70; 3) udder circumference, milk yield at $\mathrm{d} 70$ and DIM.

${ }^{2} \mathrm{NA}=$ not applicable.

${ }^{*} P<0.05 ; * * P<0.01$.

that they prefer ewes that have more than 100 DIM. It is possible, therefore, that discussion and participatory work capitalizing on the knowledge of farmers could lead to simple measurements with which farmers are familiar to substantially improve their evaluations and eventually be integrated and used in a breeding plan.

Only one farmer had a low ability to assess the production potential of ewes above $4 \mathrm{yr}$ of age; the remaining farmers had consistent correlations between their individual assessment scores and milk production traits.

\section{CONCLUSIONS}

Udder circumference appears to have a predictive ability for milk production traits. It is simple to measure or score, is repeatable between lactations, and could be useful for simple milk recording in dairy sheep. However, the addition to the udder measurements of just one milk yield recording on d 70 of lactation, or, even better, DIM values in an equation to predict total milk yield resulted in considerable improvement in predictive ability compared with using udder circumference alone.

Dairy sheep farmers from a dairy sheep production region in northern Syria can assess relatively accurately the performance of a ewe by using criteria that are integrated into local sheep-breeding knowledge and encompass the most predictive udder measurements identified in this study. These udder measurements along with simple milk and DIM recording, which can be easily measured or visualized by farmers, have practical implications for community-based breeding programs to improve milk production.

\section{ACKNOWLEDGMENTS}

The support of the Government of Japan is appreciated. The authors also thank the farmers of the Abu Jabbar and Tal Tahin communities who participated in the scoring of ewes.

\section{REFERENCES}

Caja, G., X. Such, and M. Rovai. 2000. Udder morphology and machine milking ability in dairy sheep. Pages 17-40 in Proc. 6th Great lakes Dairy Sheep Symp., Guelph, Ontario, Canada. University of Wisconsin-Madison, WI.

Casu, S., I. Pernazza, and A. Carta. 2006. Feasibility of a linear scoring method of udder morphology for the selection scheme of Sardinian sheep. J. Dairy Sci. 89:2200-2209.

Charon, K. M. 1990. Genetic parameters of the morphological traits of sheep udder. World Rev. Anim. Prod. XXV:73-76.

Dzidic, A., M. Kaps, and R. M. Bruckmaier. 2004. Machine milking of Istrian dairy crossbreed ewes: Udder morphology and milking characteristic. Small Rumin. Res. 55:183-189. 
Emediato, M. S., E. R. Siqueira, M. M. Stradiotto, S. A. Maestá, and S. Fernandes. 2008. Relationship between udder measurements and milk yield in Bergamasca ewes in Brazil. Small Rumin. Res. 75:232-235.

Epstein, H. 1985. The Awassi Sheep with Special Reference to the Improved Dairy Type. FAO Animal Production and Health paper 57 , Rome, Italy.

FAOSTAT. 2008. http://faostat.fao.org/site/573/DesktopDefault. aspx?PageID=573\#ancor Accessed Aug. 17, 2008.

Fernández, G., P. Alvarez, F. San Primitivo, and L. F. de la Fuente. 1995. Factors affecting variation of udder traits in dairy ewes. J. Dairy Sci. 78:842-849.

Fernández, G., J. A. Baro, L. F. de la Fuente, and F. San Primitivo. 1997. Genetic parameters for linear udder traits of dairy ewes. J. Dairy Sci. 80:601-605.

Gootwine, E., B. Alef, and S. Gadeesh. 1980. Udder conformation and its heritability in the Assaf (Awassi $\times$ East Friesian) cross of dairy sheep in Israel. Ann. Genet. Sel. Anim. 12:9-13.

Iñiguez, L. 2006. Characterization of small ruminant genetic resources in Central Asia, the Caucasus, West Asia and North Africa. Pages 34-39 in Options and Strategies for the Conservation of Farm Animal Genetic Resources: Report of an International Workshop. CGIAR System-wide Genetic Resources Programme (SGRP)/ Biodiversity International, Rome, Italy.

Iñiguez, L., and M. Hilali. 2009. Evaluation of Awassi genotypes for improved milk production in Syria. Livest. Sci. 120:232-239.

Kassem, R. 2005. Small ruminant breeds of Syria. Pages 183-237 in Characterization of Small Ruminant Breeds in West Asia and North Africa, I. West Asia. L. Iñiguez, ed. International Center for Agricultural Research in the Dry Areas (ICARDA), Aleppo, Syria.

Labussière, J. 1988. Review of physiological and anatomical factors influencing the milking ability of ewes and the organization of milking. Livest. Prod. Sci. 18:253-273.

Labussière, J., D. Dotchewski, and J. F. Combaud. 1981. Caractéristiques morphologiques de la mammelle des brebis Lacaune. Méthodologie pour l'obtention des données. Relations avec l'aptitude à la traite. Ann. Zootech. 30:115-136.
Legarra, A., and E. Ugarte. 2005. Genetic parameters of udder traits, somatic cell score, and milk yield in Latxa sheep. J. Dairy Sci. $88: 2238-2245$

Mavrogenis, A. P., C. Papachristoforou, P. Lysandrides, and A. Roushias. 1988. Environmental and genetic factors affecting udder characters and milk production in Chios sheep. Genet. Sel. Evol. 20:477-488.

McKusick, B. C., Y. M. Berger, and D. L. Thomas. 1999. Preliminary results: Effects of udder morphology on commercial milk production of East Friesian crossbred ewes. Pages 49-60 in Proc. 5th Great lakes Dairy Sheep Symp., University of Wisconsin-Madison, Dept. Anim. Sci., and University of Vermont, Center for Sustainable Agriculture.

Milerski, M., M. Margetín, A. Lapstreak, D. Apolen, J. Špánik, and M. Oravcová. 2006. Relationships between external and internal udder measurements and the linear scores for udder morphology traits in dairy sheep. Czech J. Anim. Sci. 51:383-390.

Rovai, M., G. Caja, and X. Such. 2008. Evaluation of udder cistern and effects on milk yield of dairy ewes. J. Dairy Sci. 91:46224629 .

Rovai, M., X. Such, J. Piedrafita, G. Caja, and M. R. Pujol. 1999. Evolution of mammary morphology traits during lactation and its relationship with milk yield of Manchega and Lacaune dairy sheep. Pages 107-109 in Milking and Milk Production of Dairy Sheep and Goats. EAAP Publ. No. 95. F. Barillet and N. P. Zervas, ed. Wageningen Pers, Wageningen, the Netherlands

Snedecor, G. W., and W. G. Cochran. 1967. Statistical Methods. 6th ed. The Iowa State University Press, Ames.

Snowder, G. D., L. D. Van Vleck, A. D. Knight, T. R. Kellom, and C. M. Bromley. 2001. Usefulness of subjective ovine milk scores: II. Genetic parameter estimates. J. Anim. Sci. 79:869-876.

Such, X., G. Caja, and L. Pérez. 1999. Comparison of milking ability between Manchega and Lacaune dairy ewes. Pages 45-50 in Milking and Milk Production of Dairy Sheep and Goats. EAAP Publ. No. 95. F. Barillet and N. P. Zervas, ed. Wageningen Pers, Wageningen, the Netherlands.

Thomas, D. L. 2003. Calculation of yield of milk, fat, and protein in dairy sheep. J. Dairy Sheep Assoc. North America 2:4-6. 